\title{
Should doctors provide futile medical treatment if patients or their proxies are prepared to pay for it?
}

\author{
D J McQuoid-Mason, BComm, LLB, LLM, PhD \\ Centre for Socio-Legal Studies, University of KwaZulu-Natal, Durban, South Africa
}

Corresponding author: D J McQuoid-Mason (mcquoidm@ukzn.ac.za)

\begin{abstract}
Ethically and legally doctors are not obliged to provide futile treatment to patients, even if the patient or their proxies are prepared to pay for it. However, it may be justified where such treatment is harmless and has a placebo effect. In deciding about a request for futile treatment, doctors should be guided by the ethical principles of patient autonomy, beneficence, non-maleficence and justice. Guidelines are provided to assist doctors in making such decisions. Where futile treatment is withdrawn or refused, palliative care must always be offered. If it is decided to withdraw or refuse treatment, the patient or their proxy should be given the opportunity to contact another practitioner or institution that may be prepared to offer such treatment.
\end{abstract}

S Afr Med J 2017;107(2):108-109. DOI:10.7196/SAMJ.2017.v107i2.12191

Is it ethical and legal for doctors to provide futile medical treatment if patients or their proxies are prepared to pay for it and what should doctors do in this situation? In answering this question the following must be considered: ( $i$ ) the meaning of futile medical treatment; (ii) the ethical principles with regard to futile treatment; (iii) its legal position; and (iv) the action doctors should take when faced with such requests.

\section{Futile medical treatment}

The concept of 'futile medical treatment' is controversial because of the current emphasis on patient autonomy and rights. According to the American Medical Association it cannot be meaningfully defined ${ }^{[1]}$ Hippocrates stated that doctors should refuse to treat patients in cases where 'medicine is powerless. . $^{[2]}$

The World Medical Association Medical Ethics Manual ${ }^{[3]}$ states that a doctor has 'no obligation to offer a patient futile or non-beneficial treatment' and describes treatment as 'medically futile' when it 'offers no reasonable hope of recovery or improvement or because the patient is permanently unable to experience any benefit'. In other cases the Manual ${ }^{[3]}$ states that 'the utility and benefit of a treatment can only be determined with reference to the patient's subjective judgment about his or her overall well-being', and a patient should generally 'be involved in determining futility in his or her case', except where it 'may not be in the patient's best interests'. Doctors also 'should feel free to refuse if the treatment is unlikely to be beneficial, even if it is not harmful, although a potential placebo effect should not be discounted', implying that it is justified to prescribe a placebo if it improves a patient's quality of life. Such treatment plays a palliative care role, which differs from futile treatment. ${ }^{[4]}$

Palliative care aims at alleviating the patient's pain or suffering not curing their condition - and becomes futile if it can no longer reduce the patient's pain or suffering. ${ }^{[5]}$ Futile treatment usually means treatment that is ineffectual and inadequate to cure the patient or alleviate their suffering - it is a 'clinical action serving no useful purpose in attaining a specified goal for a given patient. ${ }^{[4]}$

\section{Ethical theories and principles relating to futile treatment}

Once it is decided that further treatment is futile, can it be terminated or refused against the wishes of the patients or their legal proxies?
Many ethical theories regarding futile treatment could be invoked, such as virtue ethics, Kantian deontology, utilitarianism, communitarianism, liberal individualism, social contract theory, ethics of care, and casuistry. ${ }^{[6]}$ However, most of these are not useful for practitioners. The same applies to classifications of futility into: ${ }^{[7]}$ (i) 'physiological futility' - where the treatment cannot achieve its physiological effect; (ii) 'imminent-demise futility' - where the patient will die soon despite the proposed medical treatment; (iii) 'lethal condition' - where the patient has a terminal illness that treatment will not affect and the patient will die soon; and (iv) 'quality futility' - where the treatment fails to allow the patient to lead an acceptable quality of life. ${ }^{[1]}$

Another suggestion is to distinguish between the effect of a treatment', i.e. how it may alter 'some bodily function', and 'the benefit of a treatment', i.e. 'something that can be appreciated by the patient. ${ }^{[8]}$ This has also been referred to as 'physiological futility' and 'normative futility, ${ }^{\prime 9]}$ and is consistent with the recommendations of the Manual ${ }^{[3]}$ that patients or their proxies should be involved in discussions about withdrawal of treatment on grounds of futility. It has also been suggested that 'medical futility' exists when: 'there is a goal'; 'there is an action and activity aimed at achieving this goal'; and 'there is virtual certainty that the action will fail in achieving this goal. ${ }^{[10]}$ However, the bounds of 'virtual certainty' have not been drawn, and it has been suggested that it applies where the chances of the treatment succeeding are $<1-5 \% .{ }^{[4]}$

However, I prefer to use 'principlism', because it is the most popular and widely used approach. ${ }^{[1]}$ It refers to the commonly accepted principles of patient autonomy, non-maleficence, beneficence and justice, ${ }^{[12]}$ and has an easier practical clinical application than most other theories.

Deciding to terminate or refuse a patient's request for futile treatment causes a conflict between the principles of their right to autonomy and beneficence, non-maleficence and justice. Patients exercise patient autonomy when they demand to be treated if their prognosis is hopeless and further medical treatment is futile. However, such autonomy has limits, for instance where a patient asks a doctor to do something illegal or unethical, as in the Michael Jackson case, when the patient's right to autonomy may be overridden, and the other principles of beneficence, non-maleficence and justice should be applied. ${ }^{[13]}$ This requires 'a balance between benefits and burdens, 
including immediate detriment, inconvenience, risk of harm, and other costs. ${ }^{[14]}$ It may, for example, be 'inhumane or cruel' to prolong life where 'the pain may be so severe and the physical restraints so burdensome as to outweigh the limited anticipated benefits. ${ }^{[14]}$ Conversely, it may be justified to prescribe a futile medication with a placebo effect. ${ }^{[3]}$

When deciding to terminate or refuse treatment against a patient's or their proxy's wishes because of futility, doctors must discuss this with them and decide whether it will benefit patients, if it is in their best interests, and whether it will save them from further harm. ${ }^{[1]]}$ This is an application of the principles of beneficence and non-maleficence. Families and relatives usually do not want to see their loved ones suffer, and are grateful when doctors guide them about withdrawing futile treatments. ${ }^{[4]}$ Where such treatment is withdrawn, patients should be given palliative care, unless that has also become ineffectual and futile in end-of-life situations. ${ }^{[5]}$

Apart from the principles of beneficence and non-maleficence, doctors must also consider whether the termination or refusal of treatment will lead to a just and equitable distribution of medical resources for others dependent on the healthcare system. This includes the private sector, where futile care may prevent non-terminally ill patients from accessing life-support equipment and intensive care units. ${ }^{[15]}$ This is in line with the principle of justice. This approach has been criticised as the beginning of the 'slippery slope' that uses medical futility as a cover for 'rationing of resources' and reducing the 'costs of end-of-life care. ${ }^{[4]}$ However, the principlism approach, based on beneficence, nonmaleficence and justice, balances the subjective concerns of patients or their surrogates and the medical profession with the objective concerns of society regarding the just allocation of medical resources.

The ethical principles provide useful guidelines to practitioners and the courts when determining how a reasonably competent doctor would be expected to behave in particular circumstances, although the courts are not bound by these principles. ${ }^{[16]}$

\section{The law in relation to futile treatment}

Doctors have no legal duty to provide useless or futile treatment to patients whose prognosis is hopeless. ${ }^{[17]}$ These situations often arise when end-of-life decisions must be made. The South African Constitutional Court has ruled that a state hospital is not obliged to provide renal dialysis to a chronically ill person requesting such treatment, who does not qualify for it in terms of the hospital's criteria. ${ }^{[18]}$ The court stated that it would 'be slow to interfere with rational decisions taken in good faith by the political organs and medical authorities whose responsibility it is to deal with such matters'. ${ }^{[18]}$ The court refused treatment by renal dialysis based on the justice principle that sometimes the courts must 'adopt a holistic approach to the larger needs of society rather than to focus on the specific needs of particular individuals within society. ${ }^{\text {[18] }}$

Courts in the UK, in several cases dealing with the termination or withholding of futile treatment, have also deferred to the decisions of the doctors - even when it was against the wishes of patients or their surrogates. ${ }^{[19]}$ They have stated that 'in a perfect world any treatment which a patient ... sought would be provided if doctors were willing to give it, no matter the cost ... . It would, however, be shutting one's eyes to the real world if the court were to proceed on the basis that we do live in such a world. ${ }^{[19]}$ This statement was approved by the South African Constitutional Court in the abovementioned renal dialysis case. ${ }^{[18]}$ The UK Court of Appeal has also stated that 'no patient can require a doctor to treat him against his best clinical judgment. ${ }^{[20]}$
What should doctors do when futile medical treatment is requested for patients who can pay for it themselves or through their proxies?

Ethically ${ }^{[3]}$ and legally ${ }^{[17]}$ doctors are not obliged to offer patients futile or non-beneficial treatment. The ethical principles provide useful guidelines to practitioners and the courts, but the courts may decide not to follow them. ${ }^{[16]}$

When doctors receive requests for futile aggressive medical treatment, by patients who can afford to pay for it or through their proxies, they should consider the following:

- Decide whether or not the requested treatment is futile and confirm this by obtaining another opinion from a specialist in the field. ${ }^{[21]}$

- Use the ethical principle of patient autonomy to consider the request for such treatment by the patient or their proxy; then use the other principles to make a decision. ${ }^{[4,13]}$

- Use the ethical principles of beneficence and non-maleficence to decide whether it would be ethical to provide such treatment by determining whether it will benefit or cause them harm. Balance the benefits against the burdens of continuing the treatment, ${ }^{[4,14]}$ including whether it could have a placebo effect. ${ }^{[3]}$

- Use the justice principle to decide whether such treatment will divert resources away from non-terminal or curable patients with positive prognoses - in the public and private sectors. ${ }^{[14,15]}$

- Having decided that the treatment is futile, and that it is ethically justified to discontinue it, explain the reasons for this decision to the patient or their proxy. ${ }^{[4,2]}$

- Ensure that if treatment is discontinued, the patient is provided with palliative care. ${ }^{[4]}$

- Provide the patient or their proxy with an opportunity to transfer the former to the care of another practitioner or facility that may assist, ${ }^{[4]}$ e.g. terminal patients to a hospice.

1. Clark PA. Medical futility: Legal and ethical analysis. Virtual Mentor 2007;9(5):375-383. http://dx.doi. org/10.1001/virtualmentor.2007.9.5.msoc1-0705

Jones WHS, trans-ed. Hippocrates, vol. 2: Prognostic. Cambridge, MA: Harvard University Press, 1981:193.

3. Willams JR. Word Medical Association Medical Ethics Manual. 3rd ed. Ferney-Voltaire Cedex, France: WMA, 2015:46.

4. Kasman DL. When is medical treatment futile? A guide for students, residents and physicians. J Gen Intern Med 2004;19(10):1053-1056. http://dx.doi.org/10.1111/j.1525-1497.2004.40134.x

Intern Med 2004;19(10):1053-1056. http://dx.doi.org/10.1111/j.1525-1497.2004.40134.x
5. Stransham-Ford v the Minister of Justice and Correctional Services 2015 (4) SA 50 (GP),

5. Stransham-Ford v the Minister of Justice and Correctional Services 2015 (4) SA 50 (GP).
6. Dhai A, McQuoid-Mason D. Bioethics, Human Rights and Health Law. Cape Town: Juta, 2011:9-15.

6. Dhai A, McQuoid-Mason D. Bioethics, Human Rights and Health Law. Cape Town: Juta, 2011:9-15.
7. Brody BA, Halevy A. Is futility a futile concept? J Med Philos 1995;20(2):123-144. http://dx.doi. . Brody BA, Halevy A. Is futit
org $/ 10.1093 / \mathrm{jmp} / 20.2 .123$

8. Mason JK, Laurie GT. Mason and McCall Smith's Law and Medical Ethics. 8th ed. Oxford: Oxford 8. Mason JK, Laurie GT. Mason
University Press, 2011:476-500.

9. Schneiderman LJ, Jecker NS. Futility in practice. Arch Intern Med 1993;153(19):2195-2198. http:// dx.doi.org/10.1001/archinte.1993.00410190031004

10. Trotter G. Mediating disputes about medical futility. Camb Q Healthc Ethics 1999;8(4):527-537.

11. Moodley K, ed. Medical Ethics, Law and Human Rights. Pretoria: Van Schaik, 2011:19-30.

12. Beauchamp TL, Childress JF. Principles of Biomedical Ethics. 3rd ed. Oxford: Oxford University Press, 1994:67-113;120-184;194-249;256-302.

13. McQuoid-Mason D. Michael Jackson and the limits of patient autonomy. S Afr J Bioethics Law 2012;5(1):11-14.

14. Beauchamp TL, Childress JF. Principles of Biomedical Ethics. 3rd ed. Oxford: Oxford University Press, 1994:153-155.

15. Knox R. When medical care is futile, other patients pay the hidden price. CommonHealth 26 August 2014. http://www.wbur.org/commonhealth/2014/08/26/cost-futile-care (accessed 15 December 2016).

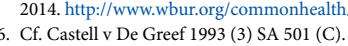

16. Cf. Castell v De Greef 1993 (3) SA 501 (C).
17. Cf. Airedale NHS Trust v Bland [1993] 1 All ER 821 (HL).

17. Cf. Airedale NHS Trust v Bland [1993] 1 All ER 821 (HL).
18. Soobramoney v Minister of Health, KwaZulu-Natal 1998 (1) SA 765 (CC).

19. R v Cambridge Health Authority, ex p B [1995] 2 All ER 129 (CA).

20. R (on the application of Burke) $v$ General Medical Council 2004 (3) FCR 579 (CA).

21. Cf. Health Professions Council of South Africa. Guidelines for the Withdrawing or Withholding of Treatment. Pretoria: HPCSA, 2008:para 4.

22. Cf. Health Professions Council of South Africa. Guidelines for the withdrawing or withholding of treatment. Pretoria: HPCSA, 2008:para 7.

Accepted 23 November 2016 